\title{
Algumas dimensões culturais da trajetória de estudantes pobres no ensino superior público: o caso da UFMG
}

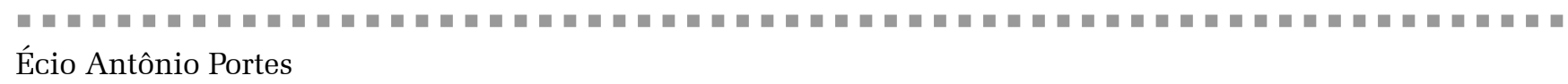

\section{Resumo}

Estuda as trajetórias de estudantes pobres em cursos altamente seletivos da Universidade Federal de Minas Gerais, como Ciência da Computação, Comunicação Social, Direito, Engenharia Elétrica, Fisioterapia e Medicina. Explica o conjunto de circunstâncias que propiciaram esse sucesso escolar. Realiza esse intento investigando a história de estudantes pobres no ensino superior no século 20, nas Faculdades de Direito de Olinda/Recife e de São Paulo e a história do atendimento a estudantes pobres empreendido pela UFMG desde o momento de sua criação. Utiliza os trabalhos que lidam com trajetórias escolares, principalmente de sociólogos franceses, como Bourdieu, De Queiroz, Lahire, Laurens e Terrail, entre outros. Os resultados confirmam a existência de estudantes pobres no ensino superior desde a implantação deste, mesmo que pouco representativa; e, como conclusão, é afirmado que a inclusão e a permanência de estudantes pobres no ensino superior brasileiro são uma tarefa de difícil execução, que se deu sem a presença de ações desenvolvidas pelo Estado. No passado, esses estudantes desenvolveram estratégias próprias que se associariam, já no século 20, a estratégias filantrópicas e institucionais empreendidas no seio da própria instituição universitária, a exemplo do que vem fazendo a UFMG ao longo do tempo. Essas ações sustentaram um grupo de estudantes pobres no interior da universidade pública, mas não puseram fim às discriminações sofridas nem minimizaram os constrangimentos econômicos perpetuados historicamente e pelos quais outros vêm passando no cotidiano universitário.

Palavras-chave: sociologia da educação; trajetórias escolares; estudantes pobres; ensino superior.

\section{Abstract \\ Some cultural dimensions in the trajectory of poor students in public higher education: \\ the case of UFMG}

This work gives priority to the historic and theoretical search necessary to the understanding of the object of study, the social and school trajectories of poor students, in the past and in the present. The new data and the proposed analyses lead us to believe that the fact of poor students being included in the Brazilian higher education and remaining at the University is not an easy task and took place without any government policies. In former times, these students developed their own strategies, which became associated, in the twentieth century, to institutional strategies, organised inside the University itself, following the example of what UFMG has been doing all this time. These actions supported a group of poor students in the public University but did not hinder prejudice nor diminished economical embarrassments, which they historically have been going through in their university routine.

Keywords: sociology of education; school trajectories; university life; poor students; higher education. 


\section{Introdução: a busca da compreensão trajetória de pobres no ensino superior}

Este trabalho tem como tema central a trajetória escolar e as vivências universitárias de um grupo de estudantes pobres que tiveram acesso, através do vestibular, a cursos altamente seletivos da Universidade Federal de Minas Gerais (UFMG), a saber: Ciência da Computação, Comunicação Social, Direito, Engenharia Elétrica, Fisioterapia e Medicina. Trata-se de trajetórias “estatisticamente improváveis", pois elas desafiam as previsões acerca das reais possibilidades de esses jovens chegarem aonde chegaram, como vêm mostrando as pesquisas sobre o acesso ao ensino superior público.

Meu envolvimento com o tema vem de longa data e obedece a mais do que determinações individuais: trabalhei, como pedagogo, na Fundação Universitária Mendes Pimentel (Fump), ${ }^{1}$ de 1989 a 1996. Em 1993 apresentei uma dissertação de mestrado (Portes, 1993) que cuidava de investigar as trajetórias e as estratégias escolares de um grupo de 37 universitários atendidos pela Fump, até o momento que marcava a sua passagem no exame vestibular da UFMG. Mas as diferentes questões produzidas pelos universitários que procuravam pela assistência na Fump (pedagógica, psicológica, psiquiátrica, social...) demandavam aprofundamento de estudos e novas pesquisas para uma devida compreensão, principalmente dos estudantes que freqüentavam aqueles cursos mais seletivos. Os resultados dos trabalhos em equipe mostravam que aqueles poucos estudantes pobres desses cursos, mesmo beneficiados pela Fump, apresentavam um sofrimento mais acentuado nas suas vivências acadêmicas.

Uma compreensão do conceito de pobreza, que vem sofrendo uma série de alterações desde o século 19, nos ajudava no atendimento a esses sujeitos. Naquela época, pobre era todo aquele que vivia do trabalho manual, geralmente negros e mestiços; e uma mobilidade na hierarquia social, principalmente nos centros comerciais das províncias, onde os homens eram menos dependentes do que no campo, só era possível mediante arranjos e negociações: "Por maiores que fossem seu mérito e talento, o alforriado não podia transpor determinado limiar, a menos que contasse com um bom número de cumplicidades, não apenas entre outros ex-escravos, mas também no mundo dos brancos, ou no dos que assim se consideravam.” (Mattoso, 1992, p. 590).

Em uma visão macro, já no século 20, para Abranches (1995), a pobreza é “destituição, marginalidade e desproteção" dos meios de sobrevivência física, dos benefícios do progresso, do acesso às oportunidades (de moradia, escolares, habitacionais, de saúde, de trabalho, etc.), produzidas pela inoperância das políticas públicas. Ela é fruto, nesse caso, de causas “compósitas”. Em uma visão mais antropológica, Zaluar (1985, p. 41) afirma que a pobreza "é um conceito comparativo, e sua qualidade relativa aos outros gira em torno da desigualdade social”. Ela não é uma conseqüência da cultura dos pobres. Ainda nessa visão, Sarti (1996, p. 18), mesmo reconhecendo mudanças no eixo de interpretação da pobreza como ausência de direito, quando se estabelece uma relação entre pobreza e cidadania, afirma que o risco de se ver o pobre "como o avesso do que deveria ser” acaba sendo a "desatenção para a vida social e simbólica dos pobres no que ela representa enquanto positividade concreta, a partir da qual se define o horizonte de sua atuação no mundo social e a possibilidade de transposição desta atuação para o plano propriamente político”.

Mesmo se se verifica um enorme avanço com relação a inclusão de filhos de trabalhadores de baixa renda na universidade pública brasileira, principalmente em alguns cursos como Biblioteconomia, Ciências Biológicas, Ciências Sociais, Enfermagem, Engenharia de Minas, Física, Geografia, Geologia, História, Letras, Matemática, Pedagogia, Química e Terapia Ocupacional, entre outros, como mostram os estudos produzidos por Schwartzman (1992), Paredes (1994), Mercuri, Moran e Azzi (1995), Braga, Pinto e Cardeal (1996), Bezzon (1997) e Whitaker e Fiamengue (1999), é verdade, também, que pouco se avançou naquelas carreiras tradicionais, como Direito, Engenharia Elétrica, Engenharia Química, Medicina, Medicina Veterinária, Odontologia, e mesmo em carreiras mais recentes, como Ciência da Computação, Comunicação Social e Fisioterapia, tornando tão difícil o acesso a essas carreiras por alunos egressos das escolas públicas que levam pesquisadores 
da questão a concluírem que "são poucos os candidatos que desafiam a hierarquia não escrita dos cursos e carreiras" (Braga, Peixoto, Bogutchi, s/d, p. 17). É que a entrada nessas carreiras parece ser restrita àqueles que possuem um volume mais significativo de capital escolar e cultural. ${ }^{2}$

Nos anos 90, de acordo com o Perfil Socioeconômico e Cultural dos Alunos de Graduação da UFMG (1996), que utiliza a classificação social da Associação Brasileira de Institutos de Pesquisa de Mercado (Abipeme) nos dados sobre a UFMG, verifica-se a presença de $28,5 \%$ de estudantes situados na Classe C, isto é, aqueles que possuem renda familiar de até 10 salários mínimos. Pode-se saber ainda que apenas $14 \%$ dos estudantes dessa universidade possuem renda familiar de até cinco salários mínimos, sem maior precisão quanto à origem social dos pesquisados. E é nessa faixa de renda que se situam os sujeitos de minha pesquisa, filhos de motorista, aplicador de sinteco, auxiliar de topografia, carpinteiro.

Os estudos sociológicos que orientavam os trabalhos práticos e teóricos desenvolvidos por nós no interior da Fump e da UFMG evidenciavam que, para o filho do pobre, a "passagem" do mundo escolar de nível médio para o mundo universitário é complexa e afeta sobremaneira a subjetividade desses sujeitos.

Nossa compreensão sobre as manifestações trazidas até nós pelos universitários pobres se ampliou diante do trabalho de Terrail (1990), ${ }^{3}$ ao mostrar, a partir de 23 relatos biográficos de filhos de operários por ele pesquisados, que o acesso, graças a uma escolaridade prolongada, à erudição e, ao mesmo tempo , à "vida burguesa", produziu um efeito de descontinuidade nesses sujeitos. ${ }^{4}$ Diante da constatação de que as determinações sociais são excessivamente complexas, o autor decide-se por passar do "porquê" ao "como”, necessário para explicar o sucesso escolar dos filhos de operários, colocando-se uma série de questionamentos: Como se operam os itinerários escolares mais longos nas famílias operárias? O que se passa nessas famílias, entre seus membros, nas suas relações com a escola, que torna possível o sucesso? Quais as famílias que conseguem mobilizar recursos suficientes (tempo, dinheiro), capacidade de energia e inteligência a serviço da causa escolar? Existem diferentes tipos de mobilização de recursos? Qual a parte dos pais, de um lado, e dos filhos interessados, de outro? Como os filhos vivem essa história?

Dentre outras importantes conclusões, Terrail mostra o fim da ilusão do universitário filho de operário, de que se poderia negar indefinidamente a origem social ao se penetrar no mundo acadêmico e vivê-lo como um universitário qualquer. Para Terrail (1990, p. 239), o sucesso escolar dos egressos das famílias operárias implica penetrar em um universo hostil, no qual a diferença "não pode ser vivida como justaposição, mas como oposição, antagonismo, repressão das palavras e das práticas familiares".

Por sua vez, o trabalho de Laurens (1992) ampliava a nossa compreensão quanto ao processo de investigação das trajetórias escolares de filhos de operários. Os sujeitos de sua pesquisa são filhos de operários com sucesso escolar, inscritos ou que passaram por uma das treze escolas de engenharia de Toulouse. Sua pesquisa parte de uma série de questões, tais como: Quem são as exceções sociais que materializam o sucesso social? Qual é o seu perfil? Quem são seus pais? Quem são os rapazes do povo, símbolos de todo um ideal social, que se tornam as elites francesas? Como é que eles chegam lá?

O que o autor tenta explicar com esse conjunto de questões é que o sucesso escolar e, em seguida, social de qualquer filho de operário não é uma história de dons ou de disposições naturais ou de acasos e circunstâncias. Essa trajetória "extravagante" é também um processo histórico, familiar e social.

O autor combina uma pesquisa quantitativa efetuada através de questionários e uma pesquisa qualitativa, a partir da reconstrução biográfica de 31 casos. Segundo Laurens, seu objetivo é colocar em evidência o comportamento estratégico dos atores sociais, de observar como eles utilizam a margem de ação que lhes deixa a indeterminação social.

Estudos iniciais (Portes, 1993; Portes, Carneiro, 1997) levaram-me a importantes indagações para a contextualização da presente pesquisa: Existiram estudantes pobres nos cursos superiores, desde os seus primórdios? Se existiram, como é que os estudantes pobres viveram a experiência acadêmica no passado? Qual foi a trajetória de acesso dos universitários pobres, no passado e no presente, aos cursos altamente seletivos? No interior destes
Utilizamos aqui o conceito de capital cultural principalmente naquele sentido de "capital cultural institucionalizado", onde o diploma confere a seu portador uma "certidão de competência cultural" e reconhecimento institucional. Ainda assim, nas páginas que seguem pode aparecer uma utilização que contemple o capital cultural no estado incorporado ou objetivado, conforme Bourdieu, In: Nogueira, Catani (1998).

3 Outros importantes trabalhos, tais como o de De Queiroz (1981), Sirota (1994), Zeroulou (1988) e Zago (1990, 1991), também orientavam as nossas práticas na Fump; mesmo que não tratassem de estudantes universitários, eles foram fundamentais para se conhecer a relação família/escola nos meios populares. Temos ainda o trabalho de Willis (1991), importante para se conhecer as atitudes de jovens filhos de trabalhadores ante o processo de escolarização.

${ }^{4}$ É importante ressaltar que essa "descontinuidade" é também percebida, no caso de estudantes brasileiros, por Viana (1998). 
cursos, como é que se processa a vida cotidiana desses sujeitos? Como as condições materiais de existência afetam esses sujeitos no decorrer da aventura universitária?

Para respondê-las, este trabalho cuida de pesquisar, descrever e analisar o estudante pobre no ensino superior, mais especificamente na UFMG, procurando oferecer uma compreensão mais específica da aventura escolar empreendida por este tipo de sujeito, compreensão que possa desvelar aspectos ignorados ou acobertados por práticas investigativas que cuidaram de estudar o ensino superior de forma estrutural, abrangente. Enfim, o meu objetivo é dar visibilidade ao estudante pobre no brutal e desigual jogo de acesso e permanência no ensino superior público, lá onde ele é mais difícil de ser jogado, nos cursos muito seletivos.

Ter o estudante pobre como objeto de estudo na perspectiva acima colocada se justifica quando observamos que esse tipo de estudante não tem se constituído, ao longo do tempo, objeto privilegiado de pesquisa. É o que nos mostra um levantamento efetuado em publicações reconhecidas na área da educação, como a Revista Brasileira de Estudos Pedagógicos, os Cadernos de Pesquisa da Fundação Carlos Chagas, a Revista Brasileira de Educação, a Educação em Revista da Faculdade de Educação da UFMG, e mesmo resumos de Teses em Educação publicados pela ANPEd Associação Nacional de Pós-Graduação e Pesquisa em Educação. Essas observações valem também para o Núcleo de Pesquisas sobre Ensino Superior da Universidade de São Paulo (Nupes).

Ao contrário, em outros países, como a França, por exemplo, existe um mapeamento sobre os estudantes universitários, que compreende: a maneira de estudar (Lahire, 1997b); suas condições de vida (Grignon et al., 1996); as formas de aprendizado do "ofício de estudante” (Coulon, 1995); como é o mundo vivido pelos estudantes (Galland et al., 1995); as desigualdades observadas quando da seleção às carreiras universitárias (Bisseret, 1974); e, ainda, a tentativa de compreender a experiência, os comportamentos dos estudantes e suas formas de viver os estudos e sua vida pessoal, dentro e fora da universidade francesa (Lapeyronni, Marie, 1992).
Existem ainda estudos que cuidam de explicar, prioritariamente, as trajetórias e as estratégias de universitários pertencentes aos meios populares, como os de Terrail (1990) e Laurens (1992). No contexto inglês, é importante ressaltar o trabalho de Hoggart (1975) sobre os processos vivenciados por filhos de trabalhadores que ascendem aos mais elevados níveis de ensino daquele sistema escolar.

Inspirados nos trabalhos que se ocupam com as trajetórias e as estratégias dos sujeitos provenientes das camadas populares, em meados dos anos 90, é que alguns olhares se voltaram para o universitário pobre enquanto objeto de estudo, colocando em cena alguns trabalhos, como os de Portes (1993), Muzzeti (1997), Viana (1998) e Souza e Silva (1999). Todos esses trabalhos tomam como ponto de partida o sujeito já no interior do curso superior, ou seja, observam uma trajetória de "sucesso". ${ }^{5}$ Ressalte-se ainda que boa parte desses estudos nasceu e vem se frutificando no interior do Grupo de Trabalho Sociologia da Educação da ANPEd. Fora desse espaço apareceu o artigo de Maris, Fernandes e Batista (1998), sobre os universitários favelados da cidade do Rio de Janeiro.

Portanto, ter como objeto de estudo a experiência vivida pelo estudante universitário pobre nos cursos altamente seletivos é uma opção de pesquisa que só se viabiliza quando o olhar do pesquisador se desvia das questões macroestruturais para mergulhar no interior de determinadas instituições escolares à procura de compreender, descrever e analisar o funcionamento dessas instituições, mediante novos questionamentos que procuram privilegiar as ações dos sujeitos.

A investigação de trajetórias “espetaculares" encontra apoio em pesquisas que se ocupam com casos "paradigmáticos" (Elias, 1994), ou mesmo os casos onde "os problemas de certas pessoas são particularmente elucidativos para a análise da evolução cultural”, conforme Hoggart (1975, p. 162), pois a atenção a fenômenos como a entrada e a permanência de estudantes pobres em cursos altamente seletivos da UFMG suscitam a reflexão não só sobre esses, mas também sobre o conjunto dos estudantes.

Não é sem razão que Laurens (1992, p. 30), ao justificar por que escolheu as escolas francesas de engenharia para observar os filhos de operários que adentravam seus cursos, afirma: 
Nós quisemos observar as trajetórias de sucesso escolar no meio operário lá onde elas são as mais espetaculares, a fim de fazer ressaltar fortemente a estratégia educativa familiar que elas encerram. Foi, portanto, nas escolas superiores que nós contactamos os estudantes de origem operária, naquelas fileiras onde as representações de filhos de operários são as mais fracas: aproximadamente $5 \%$.

No caso da UFMG, a origem social joga, fundamentalmente, na seleção e classificação daqueles que buscam os cursos que se situam no topo da hierarquia universitária. ${ }^{6}$ Dessa forma, não se pode esquecer, como bem nos mostra Lahire (1997b), em seu trabalho sobre a maneira de estudar dos estudantes franceses, que a origem social

[...] joga fundamentalmente: 1) sobre a possibilidade bastante desigual de acesso ao ensino superior; 2) sobre a probabilidade bastante desigual de acesso aos diferentes estabelecimentos e tipos de estudos no ensino superior; e 3) sobre a probabilidade de forte desigualdade de efetuar os estudos longos.

Ao escolher o estudante pobre, poderia, na expressão de Laurens (1992, p. 241), "retirar o véu que recobre os itinerários sociais atípicos e o sucesso escolar no meio popular”. Mas poderia também compreender por que, mesmo beneficiados pela assistência oferecida pela Fump, eles manifestam um acentuado sofrimento nas suas vivências acadêmicas, ao cursar carreiras altamente seletivas, à semelhança de estudantes ingleses bolsistas, "bem dotados" escolarmente, pesquisados por Hoggart (1975, p. 169):

O seu treino de "passador de exames" de pouco ou nada lhe serve agora. Tem dificuldade em orientar-se num mundo onde já não há um professor a quem é necessário agradar, um rebuçado no fim de cada etapa, um diploma, um lugar certo no degrau de cima. Sente-se infeliz numa sociedade imensa e confusa, ilimitada, desordenada, sem aquecimento central, na qual não são nem os mais trabalhadores, nem os mais espertos, que recebem os rebuçados; na qual factores imponderáveis, como a "personalidade", a "sorte", a "sociabilidade", a "ousadia”, pesam muito na balança.

\section{Aspectos metodológicos}

A proposta de pesquisa, desencadeada pelos trabalhos desenvolvidos na Fump e orientada pelos estudos empreendidos, indicava que, para se conhecerem aqueles aspectos mais atinentes à vida universitária do estudante pobre no interior de cursos muito seletivos, era necessário efetuar um acompanhamento dos jovens, evitando-se, assim, observar a sua vida universitária em um só momento.

Todavia, acreditava também que seria interessante examinar as condições históricas que foram lentamente possibilitando que estudantes pobres freqüentassem ensino superior em espaços privilegiados. Queria buscar na história a justificativa e a compreensão de elementos para a manutenção, no presente, de estudantes pobres no ensino superior público.

Como ponto de partida para a investigação das condições históricas, optei por estudar as academias jurídicas de Olinda/Recife e de São Paulo e, mais recentemente, a Universidade Federal de Minas Gerais. Aquelas, por abrigarem um dos cursos que fundam o ensino superior no Brasil; e esta, por sua reconhecida história de atendimento do universitário pobre.

Acreditava ainda que, no presente, um processo de monitoramento das circunstâncias sociais e escolares presentes e constitutivas da trajetória acadêmica, vivenciadas pelo universitário egresso das camadas populares no espaço da universidade, pudesse ser realizado através dos arquivos da Fump, do histórico escolar produzido pelos entrevistados na UFMG e pelas entrevistas e relatos coletados no decorrer de quatro semestres. Ele poderia propiciar a reconstrução do clima em que se estabeleceu o jogo pela permanência no sistema escolar, seja na educação básica, seja no ensino superior. Diante desse propósito, escolhemos seis universitários, um para cada um dos seguintes cursos: Ciências da Computação, Comunicação Social, Direito, Engenharia Elétrica, Fisioterapia e Medicina.

Determinaram a escolha desses cursos as notas de aprovação no vestibular, vistas aqui mediante o percentual mínimo de acerto necessário para se entrar em cada ramo de ensino da UFMG - esse foi o critério por mim escolhido para a definição de cursos altamente seletivos. ${ }^{7}$ No meu

\footnotetext{
${ }^{6}$ Para Braga, Peixoto e Bogutchi (s/d, p. 11), "em apenas cinco carreiras - Medicina, Odontologia, Veterinária, Fisioterapia e Comunicação Social - verificou-se um decréscimo do percentual de candidatos oriundos da escola pública. Em todas elas, a fração de concorrentes da escola pública já era pequena em 1992, confirmando que a seletividade social na escolha da carreira está se tornando mais intensa.[...] Estamos tratando aqui de processo seletivo intrínseco a estudantes que reconhecem não ter condições de concorrência em cursos de maior prestígio social. Aqueles que desconhecem essa realidade pagam um custo elevado por sua desinformação. A título de exemplo, mencionamos que, para o período 1992-1999, no curso de Direito, de cada oito candidatos com FSE (fator socioeconômico) maior do que 7 (a escala varia de 0 a 10 ), um foi aprovado, enquanto que, entre os candidatos com FSE menor do que 3, apenas um em cada cem é bem sucedido".

${ }^{7}$ Não é sem razão que Almeida (1999, p. 51) afirma que "Se o vestibular pode, de fato, ser considerado como um indicador de excelência, o vestibular para os cursos que atraem os candidatos mais preparados seria o indicador mais eficaz dessa excelência”.
} 
entendimento, se o vestibular é uma forma reconhecida de seleção dos diferentes candidatos às diferentes carreiras, a análise de uma série histórica de resultados do vestibular pode indicar com segurança uma hierarquia nas carreiras universitárias. Esse critério identificou uma hierarquia existente entre as carreiras e mostrou ainda que variações no decorrer dos sete anos pesquisados são bastante sutis. Por exemplo, no período privilegiado por mim (1990-1996), o Curso de Ciências da Computação aparece como o curso que mais demanda capital escolar.

$O$ acesso aos estudantes se deu através da Fump. De posse do "perfil” do estudante de interesse da pesquisa, as assistentes sociais separavam os questionários socioeconômicos por eles preenchidos, para que, após a sua leitura, o pesquisador pudesse selecionar os jovens a serem entrevistados. Diante disso, escolhi dois estudantes por curso para iniciar os contatos. Do curso de Comunicação Social só encontrei uma jovem que atendia aos critérios da pesquisa, o que se revelou problemático, pois a estudante, após o início do acompanhamento, recusou-se a continuar participando da pesquisa, sendo impossível, portanto, substituí-la.

O Quadro 1 fornece dados sobre as características e a origem social dos sujeitos entrevistados:

Quadro 1 - Características e origem social

\begin{tabular}{|c|c|c|c|c|c|c|c|}
\hline $\begin{array}{l}\text { Idade de } \\
\text { entrada } \\
\text { UFMG }\end{array}$ & CURSO & $\begin{array}{c}N^{\circ} \\
\text { de } \\
\text { Irmãos }\end{array}$ & $\begin{array}{l}\text { Posição } \\
\text { Frátria }\end{array}$ & \multicolumn{2}{|c|}{ Escolaridade } & \multicolumn{2}{|c|}{ Profissão/ldade } \\
\hline 18 & Fisioterapia & 2 & $1^{\circ}$ & Primário & Ginasial & Motorista/47 & Do lar/43 \\
\hline 19 & Com. Social & 2 & $3^{\circ}$ & Ginasial & Ginasial & Motorista/55 & Do lar/49 \\
\hline 19 & C. Comput. & 2 & $3^{\circ}$ & Primário & Normal & $\begin{array}{l}\text { Motorista/71 } \\
\text { Falecido }\end{array}$ & $\begin{array}{l}\text { Costureira } \\
\text { Professora/56 }\end{array}$ \\
\hline 19 & Direito & 1 & $1^{\circ}$ & Primário & Ginasial & $\begin{array}{l}\text { Marceneiro/42 } \\
\text { Falecido }\end{array}$ & Costureira/51 \\
\hline 20 & Eng. Elétrica & 3 & $2^{\circ}$ & Primário & Primário & Raspador Taco/49 & Do lar/45 \\
\hline 24 & Medicina & 1 & $1^{\circ}$ & Primário & Primário & Aux. Topografia/60 & Do lar/54 \\
\hline
\end{tabular}

A expectativa era de que as entrevistas efetuadas no decorrer do acompanhamento permitissem reconstituir as trajetórias sociais e escolares dos estudantes e deixassem à mostra a vida de estudante universitário, permitindo assim traçar as possibilidades e os limites da experiência acadêmica. O número de entrevistas variou conforme a disponibilidade dos sujeitos investigados. Mas efetuei, no mínimo, três entrevistas com cada um, com duração média de duas horas, sempre após o término do semestre acadêmico. Queríamos captar as mudanças ocorridas na vida (acadêmica e social) dos sujeitos.

Os temas que orientaram as entrevistas foram a condição econômica do universitário, a vida de estudante dentro e fora do campus e a vida acadêmica propriamente dita, principalmente naqueles aspectos atinentes à relação com os professores, com os colegas, a atuação na sala de aula e o desempenho acadêmico.
O tipo de entrevista efetuada, mesmo que orientada por alguns pressupostos já enunciados, comportava uma larga margem de posicionamento dos entrevistados, revelado na sua disposição para falar de sua vida (escolar ou não). Essa disposição ofereceu elementos que não foram privilegiados nas perguntas do entrevistador, mas que se associam, completam e dão sentido àqueles. Para Kaufmann (1996, p. 63) trata-se da "vontade de falar" do entrevistado.

As pesquisas que investigam as trajetórias escolares do estudante pobre, no Brasil, são muito recentes, como mostram os trabalhos de Portes (1993, 1998, 2000), Viana (1998, 2000), Mariz, Fernandes e Batista (1998) e Souza e Silva (1999). De certa forma isso nos leva a pensar a questão do universitário pobre a partir de uma matriz teórica proveniente de estudos internacionais. Esses aparecem vincados por uma forma de pensar construída noutro espaço, noutras circunstâncias, que 
guardam algumas similaridades com o caso brasileiro. Ainda não temos como escapar das dificuldades metodológicas e teóricas colocadas pelos problemas que os estudos sobre o universitário pobre vêm suscitando, mesmo que pesquisadora como Viana (2000, p. 58) aponte, acertadamente, que os estudos nesse campo não podem se restringir à descrição formal das trajetórias, pois correm o risco de ocultar "dimensões fundamentais das biografias - facilitadoras ou dificultadoras da sobrevivência no sistema escolar -, e que ao mesmo tempo as diferenciam”.

Uma saída apontada pelo meu trabalho é investir mais esforços na reconstrução da dimensão histórica da questão. Os dados que colocamos em tela nos levam a crer que existem fontes importantes, pouco pesquisadas, que podem dar um contorno diferente do até então oferecido à compreensão da educação dos pobres no ensino superior brasileiro, fontes que podem desvelar dados até aqui ocultados pela opção de trabalho do pesquisador, pelo esquecimento histórico da questão por aqueles que investigam o ensino superior ou mesmo pela ideologia, que ditou por um bom tempo os rumos do que deveria ou não ser pesquisado em educação.

\section{A presença de estudantes pobres no ensino superior: da pobreza negada à assistência institucionalizada}

As minhas investigações provam que existiram estudantes reconhecidamente pobres nos cursos de Direito desde o momento de sua criação. É verdade, também, que se trata de uma ínfima minoria, "estatisticamente improvável”, que pouca visibilidade tem no conjunto dos dados e de difícil caracterização, o que exige do pesquisador, no sentido de evitar a sedução colocada pelos dados, não tomar de imediato o "falso" como "verdadeiro". É que existem, nos registros, estudantes que são classificados como pobres, mas que, na verdade, constituem casos de "falsos pobres". Em todo caso, está presente um sinal de diversidade cultural no interior das academias jurídicas no século 19. Elas não eram completamente refratárias ao estudante pobre, sem que com isso pudessem ser enquadradas como instâncias democráticas do ponto de vista do acesso e da permanência.
A forma como esses estudantes pobres aparecem na literatura, nas diversas crônicas produzidas em diferentes períodos, guardam algumas características importantes (Bevilaqua, 1927; Nogueira, 1907-1912 (nove volumes) e Vampré, 1977). A primeira delas refere-se ao fato de o estudante ser "brilhante", ter vencido as adversidades e ter galgado postos importantes na República. Essa forma restaura, redime e encobre a pobreza, ocultando as condições reais nas quais esses sujeitos conseguiram construir uma carreira acadêmica no interior de um espaço que discriminava o pobre. Muitos deles foram ser, posteriormente, catedráticos nos cursos jurídicos, reforçando mais ainda o silêncio dos cronistas sobre as misérias por eles vividas, que, nos dizeres de Vampré, são relembradas somente para realçar os méritos. Mas essa forma de ver o sucesso de uns reforçava também a discriminação de outros: aqueles pobres que tiveram acesso ao ensino superior e não "venceram" é porque eram uns "fracos", "vis" e "pusilânimes" que pereceram às primeiras adversidades.

Outras características merecedoras de registros e que denunciam a presença de pobres no interior dos cursos jurídicos, encontradas na literatura consultada, são cor e idade, utilizadas para reforçar os feitos daqueles estudantes que destoavam do conjunto dominante. A essas características se somam os aspectos anedótico e folclórico que envolvem os registros obtidos sobre os estudantes. As minhas análises mostram que o fato de ser uma figura folclórica ou pertencer ao anedotário institucional parece ser a razão de merecer registro, o que se dá de forma cômica, engraçada, disfarça os preconceitos e encobre as discriminações observadas na prática pedagógica de diferentes professores. Nesse caso, o anedótico e o folclórico, encerrados em si mesmos, podem mascarar uma série de circunstâncias sociais vividas pelos atores, aqui caricaturados, em um cotidiano de penúrias, para se manterem no interior das academias. Cabe ainda ressaltar, mais uma vez, que esses casos folclóricos surgem de um tipo de pobreza particular, e não da pobreza em geral, que é a pobreza de determinados estudantes que tiveram acesso às academias, onde as regras eram determinadas pela sobra da riqueza material e cultural daqueles que as dominavam. 
A trajetória escolar desses estudantes era marcada pela ausência de um sistema de educação organizado, característica mais geral do Império, que os obrigava, após aquisição das "primeiras lições”, a peregrinar de cidade em cidade, sempre merecendo favores de padres, correligionários políticos e parentes, em busca da aquisição dos saberes necessários para enfrentar os "preparatórios”, como ilustra a biografia de Tobias Barreto, que freqüentou para mais de sete espaços escolares pelo interior de Sergipe e Bahia até ser admitido na Faculdade de Direito de Olinda/Recife (Romero, 1903). Havia também aqueles que ingressavam na carreira eclesiástica como meio de obter a proteção da Igreja, na figura de clérigos e instituições a ela ligadas, como via de acesso ao conhecimento e à construção de um certo capital cultural.

Efetuados os preparatórios, em todos os casos investigados, os estudantes lançaram mão, como estratégia de sobrevivência no interior (e fora) das academias, do trabalho remunerado, desempenhando modestas funções, como fiscal, porteiro, escrevente, seleiro, caixeiro de livraria, amanuense e arquivista. Mas, como acumularam os conhecimentos necessários para ingresso nas academias (e eram bons escolares), foram, sobretudo, mestres particulares ou mesmo professores do Curso Anexo às Academias. Ainda existiram também aqueles que mereceram a ajuda de terceiros, na figura de instituições escolares, por intermédio de seus diretores e mesmo de amigos.

É importante acrescentar que a estratégia do trabalho remunerado, a estratégia de ingresso na carreira eclesiástica e a ajuda de outrem, presentes na trajetória do estudante pobre, podem aparecer associadas. Esses fatores são interdependentes, completam-se na estruturação das ações dos sujeitos, no sentido de multiplicar esforços para garantir uma trajetória com um mínimo de sobressaltos e um futuro mais promissor.

Entretanto, a aventura do estudante pobre que freqüentou o curso jurídico nas academias foi uma aventura solitária, do ponto de vista institucional; nada se encontrou nos documentos investigados que permitisse alimentar hipótese de uma preocupação institucional - qualquer que fosse para com aqueles poucos estudantes pobres. Havia, sim, uma solidariedade e, por vezes, uma caridade do grupo circundante para com aqueles mais miseráveis, mas não "resignados" com sua situação escolar e social. Nesse período a pobreza não era admitida, nem pela instituição e, tampouco, pelo estudante. Trata-se do período da pobreza negada.

Já no século 20, quando voltamos os nossos olhares para os estudantes da UFMG, as minhas pesquisas, efetuadas a partir das atas do Conselho Universitário, de uma documentação atinente aos cursos que deram origem a essa instituição e da descoberta dos inéditos documentos da Caixa dos Estudantes Pobres Edelweiss Barcellos (Cepeb), mostram que a permanência, no ensino superior, de um conjunto significativo de estudantes só foi possível porque estes se "beneficiaram" de uma série de iniciativas do reitor Mendes Pimentel, ${ }^{8}$ do trabalho efetuado pela Cepeb e das iniciativas do professor Baêta Viana na estruturação da Fump (Portes, 2003). É que essas iniciativas admitiam a presença de pobres no interior da instituição universitária e, assim, desenvolveram ações no sentido de tornar possível a permanência desses sujeitos na universidade. A fundação da UFMG marca o momento em que a pobreza é institucionalmente admitida. As ações institucionais irão sobrepor aquelas ações individuais, filantrópicas, mesmo que fundamentais para a manutenção do estudante pobre, em um determinado momento, estruturando de tal forma a Fump que, nos nossos dias, suas ações contribuem para modificar a visão da pobreza: hoje ela é assumida pelo próprio universitário. Agora, a ajuda é reivindicada. Neste caso, receber ajuda é um direito fundamental.

Ainda assim, um forte elo existente entre os estudantes pobres, nos diferentes períodos, é o constrangimento econômico ao qual eles vêm sendo submetidos historicamente. Os dados do passado e do presente permitem que eu fale de um efeito de durabilidade e permanência desse fenômeno no tempo. Se a condição econômica não é determinante das ações e práticas do estudante pobre - em um passado e em um presente -, ela é um componente real, atuante, mobilizador de sentimentos que comumente produzem sofrimento neste tipo de estudante e ameaçam sua permanência na instituição.

Denomino efeito de durabilidade e permanência ao poder que determinados 
fenômenos sociais têm de se prolongar no tempo, mesmo em espaços diferentes, modificados, produzindo efeitos, no presente, que guardam similaridades possíveis de ser identificadas em um passado mais distante, efeitos que tendem a fazer crer que esses fenômenos são "normais" e inerentes aos sujeitos, independentemente de sua condição ou origem social. Por exemplo, a diferença da idade de formatura observada entre os estudantes pobres e aqueles mais favorecidos permanece, seja em um passado mais distante, seja em um presente, como constataram as pesquisas de Portes (1993); Viana (1998) e Souza e Silva (1999).

Outra forte ligação entre os estudantes pobres que também apresenta efeito de durabilidade e permanência é o bom desempenho escolar observado no decorrer das trajetórias escolares e, principalmente, no transcorrer do curso superior. A competência na aquisição do conhecimento possibilita ao estudante pobre (embora ela não garanta) uma possibilidade de filiação ao grupo que domina a cena acadêmica, à instituição à qual se liga e à sociedade, de forma mais ampla. Entrar para o mundo acadêmico e não construir conhecimento de forma a se diferenciar dos colegas (ou quando nada a eles se igualar) é se transformar em um caso "folclórico", "anedótico" ou mesmo ser uma "fraude". Ser portador de conhecimento viabiliza a permanência no espaço acadêmico. Aqui, o conhecimento significa muito mais do que manipulação e aquisição dos conteúdos escolares: a aquisição de um conjunto de códigos de decifração que possibilita múltiplas leituras do mundo.

\section{Os tempos atuais: novas estratégias para fazer frente a necessidades antigas}

Se em um passado mais distante não pudemos, ainda, acessar o trabalho escolar da família, que propiciou a trajetória de "sucesso" daqueles estudantes que romperam as barreiras (geográficas, econômicas, culturais, políticas...) colocadas para se ter acesso ao curso superior, em um presente, o trabalho escolar da família se faz notar de forma marcante na vida dos investigados, sem que, contudo, possamos falar em "investimento" ou mesmo "mobilização”, ou seja, em atitudes racionais com objetivos de escolarização do filho. Denomino trabalho escolar das famílias a todas aquelas ações - ocasionais ou precariamente organizadas - empreendidas pela família, no sentido de assegurar a entrada e a permanência do filho no interior do sistema escolar, de modo a influenciar a sua trajetória escolar, possibilitando-lhe alcançar gradativamente os níveis mais altos de escolaridade, como, por exemplo, o acesso ao curso superior. Essas ações não me parecem completamente autônomas; às vezes elas se sustentam e adquirem clareza mediante a interferência de outros sujeitos e mesmo instituições que detêm um conhecimento mais completo das possibilidades escolares e materiais do sujeito pertencente aos meios populares.

Como venho mostrando na reconstrução da trajetória escolar de sujeitos investigados, o horizonte temporal das famílias por vezes se revela muito estreito, não propiciando a elas projeções futuras de escolarização dos filhos, dando às ações das famílias um caráter de praticidade necessária para auxiliar o filho no sentido de permanencer no interior do sistema escolar (Portes, 2000, 2001). No nosso caso, a presença da família na escolarização dos filhos pode ser notada no trabalho escolar que ela desenvolve no sentido de assegurar a presença da ordem moral doméstica, oferecer atenção para com o trabalho escolar do filho, desenvolver esforços para compreender e apoiar o filho, permitir a presença do outro na vida do filho e na (re)orientação das práticas escolares da família, incentivar a eterna aproximação dos professores, efetuar a busca da ajuda material e incentivar a filiação do filho a grupo de apoio construído no interior do estabelecimento escolar.

Observa-se em todas as entrevistas efetuadas o esforço contínuo para inculcação de uma ordem moral doméstica no filho, desde tenra idade, suficientemente forte para balizar os procedimentos sociais como disposição. A ordem moral doméstica parece funcionar como um lastro para o conjunto de ações a serem empreendidas pelas famílias e pelos filhos. Trata-se de um esforço contínuo que não tem como alvo específico o "sucesso" escolar, mas, sim, uma educação mais abrangente, uma educação para a vida e uma conformação dos procedimentos. O conjunto de entrevistas efetuadas com esses sujeitos revela que não só seus procedimentos sociais, mas também os escolares, possuem a marca distintiva dessa 
formação adquirida de forma lenta e processual no interior da família.

Nota-se todo um cuidado, um rol de preocupações, pequenas intervenções das mães (principalmente) naquilo que se refere ao trabalho escolar ou indiretamente a ele ligado. Nos nossos casos, o que parece ser rentável é a presença possível, a disponibilidade em escutar, ouvir e dar atenção ao filho, permitir que ele dê conta de suas tarefas e necessidades escolares, indagá-lo sobre seu dia escolar. Essas ações são perceptíveis na busca do estabelecimento escolar e na escolha do estabelecimento (sempre público) quando viável, na luta pela matrícula, nos possíveis contatos com outras mães (na porta da escola), nas aproximações (mesmo esporádicas) com os professores, nas reuniões escolares (quando convidadas), na manutenção física da criança e dos equipamentos necessários à freqüência da escola, na atenção para as companhias dos filhos, no ato de levar à escola e buscar, na vigilância da rua. Essas situações revelam todo um cuidado dessas mães para com a escolaridade dos filhos, mesmo que elas não pensem nisso como um projeto, mesmo que não se trate de uma ação racional visando a um fim futuro, distante (por exemplo, a chegada à universidade). Para elas, trata-se de uma obrigação cotidiana que tem de ser feita, necessária para a formação do filho, para seguir em frente. ${ }^{9}$

Aparece, no conjunto das entrevistas, um trabalho de persuasão afetiva (que se torna efetivo), no sentido de se continuar a escolaridade, diante de complexos momentos vivenciados no decorrer da trajetória escolar e universitária: trabalho executado pelas famílias no interior do lar, para que o filho não se renda diante da escola em função de situações pessoais difíceis de serem vividas e de necessidades materiais de difícil controle, que denominamos de questões paralelas. Essas questões não marcam hora nem dia para acontecer. Por exemplo, a ausência do pai, por morte ou abandono do lar - situação vivida por três entrevistados - , coloca a família em situação de instabilidade, diante da falta de recursos materiais ou pensão significativa, o que jogará inevitavelmente a mãe ou o filho mais velho no mercado de trabalho.

Nota-se aqui todo um esforço da mãe para que o filho não exerça o trabalho remunerado antes de terminar o ensino médio (horizonte que se vai vislumbrando para algumas dessas famílias). Para essas mães, a entrada no mundo do trabalho parece significar um desvio de rota quase irrecuperável, danoso, no futuro, quanto à esperança de se conseguir algo mais leve como ocupação. Essa resistência da mãe irá chocar-se com as necessidades materiais da família e do próprio jovem, que, criado sob a ética do trabalho e exposto a toda uma mídia que incentiva o consumo, vê-se na obrigação moral de produzir a sua própria existência, adquirir uma autonomia mínima. Esse conflito perpassa boa parte da trajetória e, com a entrada na universidade, parece não ter fim, o que produz um enorme desgaste nas relações intrafamiliares. A atuação afetiva da família se opera no sentido de se superar essa fase, para que o filho possa seguir adiante. Esse trabalho é difícil de ser percebido, mas perpassa toda a trajetória escolar desses estudantes. É efetuado na solidão do lar e pouco compartilhado com terceiros, mas tão-somente com aqueles mais compreensivos. Não se admite que o filho esteja doente ou preocupado e incerto quanto ao projeto universitário (que pode ser também um projeto de vida) que se iniciou. Aposta-se, aqui, na capacidade do filho de processar os conselhos, as ajudas afetivas da família, e na ação do tempo: "é tudo uma questão de tempo”. Aposta-se, também, na capacidade moral do filho de superar-se diante da família, que vê nele um sujeito merecedor das preocupações e da solidariedade a ele dispensadas.

A busca da ajuda material é um fantasma constante na vida dessas famílias, principalmente com a entrada do filho na universidade. Colocar e manter um filho nos cursos de Medicina, Fisioterapia, Direito, Comunicação Social, Engenharia Elétrica ou Ciências da Computação, mesmo numa universidade pública como a UFMG, são atos que retiram a tranqüilidade da família, pois, nos meus casos, tratase de um ensino que, mesmo sendo público, é economicamente dispendioso. Exigências próprias do acadêmico e exigências características de cada curso exercem aí uma forte influência - aquelas dizem respeito a transporte, compra de livros, xerox, material escolar, roupa, calçado, aluguel, alimentação e lazer, etc., enquanto que as últimas se configuram por necessidades como, por exemplo: para quem faz Comunicação Social, coloca-se a exigência 
de se assinar revistas e jornais diversos; para quem faz Ciência da Computação, exige-se ter em casa um computador; para quem faz Direito, desde muito cedo, exige-se usar paletó, gravata, sapatos (e não tênis), etc. Tudo isso irá propiciar uma instabilidade econômica familiar capaz de refletir-se de forma preocupante naquilo que ao longo da trajetória escolar (e social) mais parecia alicerçar esse estudante: sua segurança nas questões atinentes ao escolar. Mesmo contando com a importante ajuda da Fump, observa-se uma submissão e humilhação ao pedir de forma recorrente ou aceitar ajuda material de terceiros (geralmente parentes com situação econômica mais favorável ou amigos íntimos, ou mesmo agiotas). Ajuda frágil, inconstante, mas que remedeia circunstâncias materiais e assegura condições psicológicas básicas para a continuidade dos estudos acadêmicos do filho.

O trabalho escolar das famílias pode nos ajudar a compreender que as ações de determinadas famílias pertencentes às camadas populares são diversas e recobrem significados próprios que podem ser ocultados, dependendo do olhar que se dirige a elas. Por exemplo, acredito que há uma armadilha na forma de se analisar o possível trabalho escolar de famílias populares através de regularidades típicas observadas em frações das classes médias - que configurariam investimento escolar -, como a série apontada por Nogueira (1998): acompanhamento estrito da escolaridade (tanto na escola como fora dela); estratégias de escolha do estabelecimento; relações freqüentes com os professores; ajuda regular nos deveres de casa; reforço e maximização das aprendizagens escolares; assiduidade às reuniões convocadas pela escola; utilização do tempo de exposição à televisão, etc. As famílias populares não podem se espelhar nas ações escolares mais conhecidas e identificadas das famílias de diferentes frações das classes médias. Empreender essas ações supõe capital cultural e mesmo uma disposição econômica de que as famílias populares não dispõem. Essas famílias lidam em um espaço onde a privação, a instabilidade, a insegurança e a angústia impulsionam e orientam as ações.

No nosso caso, não se pode analisar a trajetória escolar dos jovens e a conseqüente chegada e permanência no ensino superior, considerando aqui as carreiras escolhidas, sem falar do trabalho escolar das famílias. Ele está presente em todas as trajetórias reconstruídas.

Mesmo assim, a parte que cabe aos jovens nesta empreitada não é pequena. Eles demonstram ter introjetado, no decorrer da trajetória escolar, um conjunto de disposições - dedicação, atenção ao trabalho escolar, "gosto" pela escola, obediência, solidariedade, segurança e autodeterminação -, presentes na construção de um habitus favorecedor de uma permanência prolongada no interior do sistema escolar, que "dispensa" pouco a pouco a presença da família naquilo que diz respeito à escola. Esse conjunto de disposições transfere às famílias a sensação de que seus filhos "que chegaram lá" (na universidade pública) são auto-suficientes, escolarmente falando.

Entretanto, entrar para a universidade é entrar para um "mundo novo", "desconhecido". A inclusão neste novo mundo desencadeia o sentimento de que se é diferente, socialmente falando, dos colegas, a partir da percepção de um conjunto de demonstrações e das condições de vida do outro (formas de morar, roupas e acessórios utilizados, uso do carro, formas de falar, intervenções efetuadas na sala de aula, tipos de lazeres, maiores disponibilidades econômicas e desenvoltura acadêmica, entre outras). Mas entrar para a universidade é também abrir uma porta bastante larga que propicia a interação com práticas culturais mais legítimas, como teatro, cinema, literatura, artes e concertos, que não constam da formação do estudante pobre investigado, ainda que eles manifestem outras formas de envolvimento social e de práticas cotidianas, tais como audição de rádio, assistir TV, ida a barzinho, ao shopping, à feira e à casa de amigos do bairro (ou da cidade de origem), às festas e churrascos da turma de faculdade, ao Centro Esportivo Universitário e exploração das possibilidades da cidade.

Mas viver a vida universitária requer do estudante pobre manipulação eficiente de algumas circunstâncias básicas, como dar respostas às necessidades econômicas, estabelecer uma vida de estudante (dentro e fora do campus), aceitar e se fazer aceito pelos colegas, estabelecer uma relação interessada com os professores, desenvolver uma atuação na sala de aula e não se descuidar jamais do rendimento acadêmico. Mas essas circunstâncias, fundamentais 
para um processo de filiação, esbarram rotineiramente nos limites impostos pelas condições ligadas à origem social dos estudantes pobres.

Mesmo que reafirmem com seu desempenho acadêmico a construção de uma escolaridade voltada para a vida profissional futura e dela esperem uma certa redenção social, eles reafirmam também em suas representações um pessimismo originado da angústia cotidiana não só de lidar com as dificuldades da aquisição dos saberes necessários para a consecução dos estudos, que é inerente a todos os estudantes, mas originado ainda das dificuldades colocadas pelo constrangimento econômico que ameaça o sonho universitário e os aflige de modo particular.

\section{Algumas considerações finais}

Procuro mostrar neste trabalho, inicialmente, as referências que propiciaram a compreensão do problema proposto, que é entender e explicar a trajetória excepcional de um conjunto de estudantes provenientes dos meios populares e que tiveram acesso à UFMG, através do vestibular, principalmente naqueles cursos altamente seletivos, que exigem um capital escolar significativo, onde o jogo a ser jogado para a entrada, permanência e saída, com sucesso, demanda o controle de uma série de circunstâncias que passam pelo econômico, pelo cultural e pelas disposições psicológicas desenvolvidas no interior da universidade, quando do contato com diferentes sujeitos sociais.

Em busca de uma compreensão histórica, mostramos que existiram estudantes pobres nos cursos de Direito, desde o momento de sua fundação, em 1827, mesmo que esses estudantes não fossem representativos daqueles que pertenciam às camadas mais necessitadas da população. A análise da vida escolar desses estudantes pobres identificados mostra que eles passaram pelas academias jurídicas sem merecer qualquer ajuda institucional: trata-se de um momento histórico onde a pobreza tinha de ser negada. Assim, os estudantes pobres desenvolveram estratégias próprias de sobrevivência material e simbólica, interdependentes, que se consorciavam, para que pudessem permanecer no interior dos cursos jurídicos com sucesso. Essas estratégias giravam em torno do trabalho remunerado, do pertencimento aos quadros da igreja, do auxílio recebido de terceiros e das formas de convivência, de um mimetismo estratégico, desenvolvidas no interior dos cursos jurídicos, e, principalmente, a estratégia de ser um "bom aluno”. O bom desempenho acadêmico naquele período tinha o poder de amenizar diferenças sociais, assim como hoje.

Por outro lado, mostro também que, com a fundação da Universidade Federal de Minas Gerais em 1927, a compreensão que se tinha dos “necessitados”, dos "desprovidos de fortuna”, dos "moços pobres” era outra, de que os moços providos de talento tinham de merecer ajuda para que pudessem ter sucesso nos estudos. Assim, essa universidade apoiou, inicialmente, de forma pioneira, propostas filantrópicas e, posteriormente, criou uma série de mecanismos institucionais que propiciaram a permanência dos moços pobres no ensino superior em condições bastante favoráveis, para o período.

Nos dias atuais, aqueles poucos estudantes pobres que tiveram acesso ao ensino superior na UFMG, nos cursos altamente seletivos, podem ser considerados "superselecionados", pois habitam espaços acadêmicos, como mostram as estatísticas, destinados aos herdeiros culturais, onde as chances de um jovem proveniente desse meio ter acesso a tais cursos são mínimas.

Entretanto, a justificativa para que eles chegassem aonde chegaram passa, necessariamente, pelo trabalho escolar das famílias, às vezes efetuado intergeracionalmente, e por uma autodeterminação, desenvolvidos no decorrer da trajetória escolar desses jovens. Mas chegar à universidade e, principalmente, em seus espaços mais valorizados socialmente não significa garantia de permanência e saída, diplomado. Para isso, a ajuda institucional oferecida pela UFMG se faz presente de forma determinante, o trabalho da família permanece ainda como necessário, cabendo ao estudante uma eterna vigilância de todas as circunstâncias que o cercam, que giram em torno do acadêmico, do pedagógico, das disposições psicológicas e, sobretudo, das econômicas.

Por mais que o aparato institucional nessa universidade tenha evoluído, os estudantes pobres ainda não se livraram dos constrangimentos econômicos aos quais são submetidos nesses espaços altamente 
privilegiados de formação profissional e cultural. A sociedade brasileira vem evoluindo em todos os sentidos, principalmente no que diz respeito à acumulação material e quanto ao entendimento da necessária ampliação da educação para todos, com a construção de um sistema de educação que se amplia mais e mais, e, no entanto, o aparato montado para atendimento assistencial dos jovens pobres em cursos altamente seletivos guarda, ainda, traços e formas de atendimento próprios de um país que se industrializava no início do século 20. A vida cotidiana levada por esses jovens no interior da UFMG demonstra que o aparato criado para dar sustentação à aventura escolar que eles empreenderam está obsoleto e necessita ser recriado, sob o risco de transformar uma trajetória de sucesso, vista aqui na entrada desses estudantes em espaços culturais privilegiados, em uma permanência fracassada.

\section{Referências bibliográficas}

ABRANCHES, Sérgio Henrique. Os despossuídos. Crescimento e pobreza no país do milagre. Rio de Janeiro: Zahar, 1995.

ALMEIDA, Ana Maria Fonseca de. A escola dos dirigentes paulistas. 1999. Tese (Doutorado em Educação) - Universidade de Campinas, Campinas, 1999.

BEVILAQUA, Clóvis. História da Faculdade de Direito do Recife. Rio de Janeiro: Francisco Alves, 1927. 2 v.

BEZZON, Lara Andréa Crivelo. Análise do perfil sócio-econômico cultural dos ingressantes na Unicamp (1987-1994): democratização ou elitização? Núcleo de Estudos Superiores da USP, São Paulo, 1997.

BISSERET, Noëlle. Les inégaux ou la sélection universitaire. Paris: Presses Universitaires de France, 1974.

BOURDIEU, Pierre. As contradições da herança. In: BOURDIEU, Pierre (Coord.). A miséria do mundo. Petrópolis: Vozes, 1997.

BRAGA, Mauro Mendes; PINTO, Clotilde O. B. de Miranda; CARDEAL, Zenilda de Lourdes. Perfil socioeconômico dos alunos, repetência e evasão no curso de Química da UFMG. Núcleo de Estudos Superiores da USP, São Paulo, 1996.

BRAGA, Mauro Mendes; PEIXOTO, Maria Carmo L.; BOGUTCHI, Tânia F. A demanda por vagas no ensino superior: análise dos vestibulares da UFMG na década de 90. Belo Horizonte, s/d.

COULON, Alain. Etnometodologia e educação. Petrópolis: Vozes, 1995.

D’ÁVILA, José Luis Piôto. Trajetória escolar: investimento familiar e determinação de classe. Educação \& Sociedade, ano 19, n. 62, p. 31-63, abr. 1998.

DE QUEIROZ, Jean Manuel. La desorientation scolaire; sur le rapport social des familles populaires urbaines à la escolarisation. Tese (Doutorado) - Université de Paris VIII, Paris, 1981.

ELIAS, Norbert. Sociologia de um gênio. Rio de Janeiro: Zahar, 1994.

GALLAND, Olivier et al. Le monde des étudiants (sous la Direction de O. Galland). Paris: Presses Universitaires de France, 1995. 
GRIGNON, Claude; GRUEL, Loius et; BENSOUSSAN, Bernard. Les conditions de vie des étudiants. Cahiers de L'ove, Paris, n. 1, 1996.

HOGGART, Richard. As utilizações da cultura. Aspectos da vida cultural da classe trabalhadora. Lisboa: Editorial Presença, 1975. 2 v.

KAUFMANN, Jean-Claude. L'entretien compréhensif. Paris: Nathan, 1996.

LAHIRE, Bernard (Avec la collaboration de Mathias Millet et Everest Pardell). Les manières d'étudier. Enquête 1994. Cahiers de L'ove, Paris, n. 2, 1997.

LAPEYRONNI, Didier; MARIE, Jean-Louis. Campus Blues. Les étudiants face à leurs études. Paris: Seuil, 1992.

LAURENS, Jean-Paul. L sur 500. La reussite scolaire en milieu populaire. Toulouse: Presses Universitaires du Mirail, 1992.

MARIZ, Cecília L.; FERNANDES, Sílvia; BATISTA, Roberto. Os universitários da favela. In: ZALUAR, Alba; ALVITO, Marcos (Org.). Um século de favela. Rio de Janeiro: Fundação Getúlio Vargas, 1998.

MATTOSO, Kátia M. de Queirós. Bahia, século XIX: uma província no Império. Rio de Janeiro: Nova Fronteira, 1992.

MERCURI, Elizabeth; MORAN, Regina Célia; AZZI, Roberta Gurgel. Estudo da evasão de curso no primeiro ano da graduação de uma universidade pública estadual. Núcleo de Estudos Sobre Ensino Superior da USP, São Paulo, 1995.

MUZZETE, Luci Regina. Trajetória social, dote escolar e mercado matrimonial: um estudo de normalistas formadas em São Carlos nos anos 40. Tese (Doutorado em Educação) -Universidade Federal de São Carlos, São Carlos, 1997.

NOGUEIRA, Maria Alice; CATANI, Afrânio. Pierre Bourdieu - Escritos de educação. Petrópolis: Vozes, 1998.

PORTES, Écio Antônio. Trajetórias e estratégias escolares do universitário das camadas populares. Dissertação (Mestrado) - Faculdade de Administração e Educação, Universidade Federal de Minas Gerais, Belo Horizonte, 1993.

. A caixa dos pobres - A ação efetiva do assistencialismo na permanência de estudantes pobres na UFMG: 1932-1935. In: CONGRESSO DE PESQUISA E ENSINO EM HISTÓRIA DA EDUCAÇÃO EM MINAS GERAIS, 2., Uberlândia. [Anais...] Uberlândia, 6 a 9 de maio, 2003.

A relação universitário de engenharia-professor no ciclo básico do ICEx-UFMG. In: CONGRESSO BRASILEIRO DE ENSINO DE ENGENHARIA - COBENGE, 24., Manaus. Anais... Manaus, 13 a 16 de outubro 1996. v. 1, p. 351-368.

. Estratégias escolares do universitário das camadas populares: a insubordinação aos determinantes. In: PAIVA, Aparecida; SOARES, Magda (Org.). Universidade, cultura e conhecimento. A educação pesquisa a UFMG. Belo Horizonte: FAE/UFMG, 1988. p. 251-277.

. O trabalho escolar das famílias populares. In: NOGUEIRA, Maria Alice; ROMANELLI, Geraldo; ZAGO, Nadir (Org.). Família e escola. Trajetórias de escolarização em camadas médias e populares. Petrópolis: Vozes, 2000. p. 61-80.

Trajetórias escolares e vida acadêmica do estudante pobre da UFMG - um estudo a partir de cinco casos. Tese (Doutorado) - Faculdade de Educação, Universidade Federal de Minas Gerais, Belo Horizonte, 2001. 
PORTES, Écio Antônio; CARNEIRO, Luiz Carlos Brant. O trabalho pedagógico e psicológico com universitários da UFMG: a busca da construção do sujeito. Comunicações, Piracicaba, Ano 4, n. 2, p. 31-43, 1997.

ROMERO, Sylvio. História da literatura brasileira. Rio de Janeiro: Garnier, 1903. v. 2.

SARTI, Cynthia Andersen. A família como espelho. Um estudo sobre a moral dos pobres. São Paulo: Autores Associados, 1996.

SCHWARTZMAN, Simon. Posição social da família e experiência universitária Núcleo de Estudos sobre Ensino Superior da USP, São Paulo, 1992.

SIROTA, Regine. Escola primária no cotidiano. Porto Alegre: Artes Médicas, 1994.

SOUZA; SILVA, Jailson de. "Por quê uns e não outros?" Caminhada de estudantes da Maré para a universidade. Tese (Doutorado em Educação) - Pontifícia Universidade Católica do Rio de Janeiro, Rio de Janeiro, 1999.

TERRAIL, Jean Pierre. Destins ouvriers; la fin d'une classe? Paris: PUF, 1990.

UNIVERSIDADE FEDERAL DE MINAS GERAIS. Perfil socioeconômico e cultural dos alunos de graduação da UFMG. Belo Horizonte: UFMG/Fundação Universitária Mendes Pimentel - FUMP, 1996.

VAMPRÉ, Spencer. Memórias para a história da Academia de São Paulo. Brasília: INL/ Conselho Federal de Educação, 1977. 2 v.

VIANA, Maria José Braga. Longevidade escolar em famílias de camadas populares: algumas condições de possibilidade. Tese (Doutorado em Educação) - Faculdade de Educação, Universidade Federal de Minas Gerais, Belo Horizonte, 1988.

. Longevidade escolar em famílias de camadas populares - algumas condições de possibilidade. In: NOGUEIRA, Maria Alice; ROMANELLI, Geraldo; ZAGO, Nadir (Org.). Família e escola. Trajetórias de escolarização em camadas médias e populares. Petrópolis: Vozes, 2000. p. 45-60.

WILLIS, Paul. Aprendendo a ser trabalhador. Escola, resistência e reprodução social. Porto Alegre: Artes Médicas, 1991.

WHITAKER, Dulce Consuelo Andreatta; FIAMENGUE, Elis Cristina. Dez anos depois: UNESP. Diferentes perfis de candidatos para diferentes cursos (estudo de variáveis de capital cultural). Araraquara: Pesquisa Vunesp, 1999.

ZAGO, Nadir. Trabalho das crianças e escolarização no meio rural: um estudo junto às famílias camponeses do estado de Santa Catarina. In: REUNIÃO ANUAL DA ANPEd, 13. [Anais...] Belo Horizonte: UFMG, 1990.

. Perspectivas profissionais e estratégias de escolarização: um estudo junto às famílias camponesas. In: REUNIÃO ANUAL DA ANPEd, 14. [Anais...] São Paulo: USP, 1991.

. Transformações urbanas e dinâmicas escolares: uma relação de interdependência num bairro da periferia urbana. Educação, Sociedade \& Culturas, n. 7, 1997.

ZALUAR, Alba. A máquina e a revolta. As organizações populares e o significado da pobreza. São Paulo: Brasiliense, 1985.

ZEROULOU, Zaihia. La réussite escolaire des enfantes d'immigrés; l'apport d'une approche en termes de mobilisation. Revue Francese de Sociologie, Paris, v. 29, n. 3, 1988. 
Écio Antônio Portes, doutor em Educação pela Universidade Federal de Minas Gerais (UFMG), é professor adjunto da Universidade Federal de São João del-Rei (UFSJ). eaportes@ufsj.edu.br

Recebido em 23 de março de 2005.

Aprovado em 11 de agosto de 2006. 